Revista Eletrônica de Direito Processual - REDP.

Rio de Janeiro. Ano 11. Volume 18. Número 2. Maio a Agosto de 2017

Periódico Quadrimestral da Pós-Graduação Stricto Sensu em Direito Processual da UERJ

Patrono: José Carlos Barbosa Moreira. ISSN 1982-7636. pp. 437-459

www.redp.uerj.br

\title{
ARBITRAGEM E LEX SPORTIVA: O CASO DO TRIBUNAL ARBITRAL DO ESPORTE (TAS) ${ }^{1}$
}

\section{ARBITRATION AND LEX SPORTIVA: THE CASE OF THE COURT OF ARBITRATION FOR SPORT (CAS)}

Mateus de Oliveira Fornasier Doutor em Direito Público pela Universidade do Vale do Rio dos Sinos (UNISINOS). Professor do Mestrado em Direitos Humanos da Universidade Regional do Noroeste do Estado do Rio Grande do Sul (UNIJUÍ). mateus.fornasier@gmail.com

Thiago dos Santos da Silva Mestre em Direito pela Universidade Regional do Noroeste do Estado do Rio Grande do Sul (UNIJUI). Professor do curso de Direito da Universidade da Região da Campanha (URCAMP). Advogado. thiagodyow@yahoo.com.br

RESUMO: O tema do presente trabalho é a arbitragem esportiva em âmbito global, delimitando-se o campo de estudo à atuação do Tribunal Arbitral do Esporte (TAS) como instância decisória. O problema que guiou a elaboração deste trabalho foi: de que modo o Tribunal Arbitral do Esporte (TAS) se insere como instância decisória de caráter jurídico? Sua hipótese principal é de que o Tribunal Arbitral do Esporte (TAS) é a instância máxima de uma ordem jurídica não estatal, porém global, cujas decisões são competentes não apenas para questões de interesse puramente esportivo, mas também, que estabelecem precedentes para si próprio (o que o torna autorreferente) e dizem respeito também a questões atinentes a direitos fundamentais dos atletas e organizações. Objetivo geral: analisar, a partir de noções basilares da Teoria dos Sistemas Sociais Autopoiéticos (tais como complexidade, transnacionalização e autopoiese), a Lex Sportiva e o Tribunal Arbitral do Esporte. Objetivos específicos: i)

\footnotetext{
${ }^{1}$ Artigo recebido em 10/05/2017 e aprovado em 11/07/2017.
} 
Revista Eletrônica de Direito Processual - REDP.

Rio de Janeiro. Ano 11. Volume 18. Número 2. Maio a Agosto de 2017

Periódico Quadrimestral da Pós-Graduação Stricto Sensu em Direito Processual da UERJ

Patrono: José Carlos Barbosa Moreira. ISSN 1982-7636. pp. 437-459

www.redp.uerj.br

observar a Lex Sportiva, ordem jurídica não estatal e transnacional surgida da regulação dos mais variados esportes profissionais; ii) abordar o TAS como principal centro emissor de juridicidade nessa ordem multicêntrica. Metodologia: sistêmico-construtivista. Resultados: i) a emersão da Lex Sportiva na sociedade hipercomplexa, policontextural e globalizada configura verdadeira ordem jurídica não estatal, cujas autonomia, legitimidade e força vinculante são reconhecida por ordens estatais; ii) seus processos normativos e decisórios versam acerca de matérias de alta relevância não apenas para o esporte em si, mas também sobre liberdades fundamentais; iii) o TAS, nesse âmbito, se revela verdadeira Corte máxima não estatal, cujas decisões assumem relevância fundamental para vários aspectos da vida dos envolvidos nas atividades esportivas.

PALAVRAS-CHAVE: sociedade complexa; Lex Sportiva; arbitragem esportiva; Tribunal Arbitral do Esporte.

ABSTRACT: The subject of the present work is the sport arbitration at a global level, delimiting the field of study to the performance of the Court of Arbitration for Sport (CAS) as a decision-making body. The problem that led to the elaboration of this work was: how does the Court of Arbitration for Sport (CAS) form part of the decision-making body with juridical characteristics? Its main hypothesis is that the Court for Arbitration of Sport (CAS) is the highest instance of a non-state, but global, legal order whose decisions are competent not only for issues of purely sporting interest but also that set precedents for itself (which makes it selfreferential) and also concerns about issues pertaining to the fundamental rights of athletes and organizations. Main objective: to analyze, from basic notions of the Theory of Autopoietic Social Systems (such as complexity, transnationalization and autopoiesis) the Lex Sportiva and the Arbitral Court of Sport.Specific objectives: i) to observe Lex Sportiva, a non-state and transnational legal order arising from the regulation of the most varied professional sports; ii) to approach the CAS as the main center of juridicity in this multicentric order. Methodology: systemic-constructivist. Results: i) the emergence of Lex Sportiva in the hypercomplex, polyontextural and globalized society constitutes a true non-state legal order, whose autonomy, legitimacy and binding force are recognized by state orders; ii) its normative and decision-making processes deal with issues of high relevance not only to the sport itself but 
Revista Eletrônica de Direito Processual - REDP.

Rio de Janeiro. Ano 11. Volume 18. Número 2. Maio a Agosto de 2017

Periódico Quadrimestral da Pós-Graduação Stricto Sensu em Direito Processual da UERJ

Patrono: José Carlos Barbosa Moreira. ISSN 1982-7636. pp. 437-459

www.redp.uerj.br

also to fundamental freedoms; iii) the CAS, in this context, reveals itself as a true non-state maximum court, whose decisions are fundamentally relevant to various aspects of the life of those involved in sports activities.

KEYWORDS: complex society; Lex Sportiva; sports arbitration; Court for Arbitration of Sport.

\section{INTRODUÇÃO}

O tema do presente trabalho é a arbitragem esportiva em âmbito global, delimitandose o campo de estudo à atuação do Tribunal Arbitral do Esporte (TAS) como instância decisória.

A Lex Sportiva seria um exemplo de campo de estudos interessantes dentro do chamado Direito Transnacional. ${ }^{2}$ Os conflitos (criativos ou destrutivos) entre essa ordem jurídica e as demais que surgem no globo para além do plano estatal - sendo que, no que tange ao potencial criativo de tal esfera jurídica, a Lex Sportiva, com suas várias ordens "internas" (relacionadas a federações nacionais dos mais variados esportes) e "externas" (muitas vezes relacionadas com as instâncias recursais arbitrais internacionais do esporte) é um exemplo de objeto de estudos do mais significativo pluralismo jurídico da atualidade.

Há características peculiares da Lex Sportiva que a tornam um interessante campo de estudos jurídicos. Em primeiro lugar, a sua alta complexidade (contendo várias instâncias executivas, legislativas e judiciárias, no que tange à regulação e à regulamentação do esporte mundial). Em segundo lugar, pela hibridez da regulação do esporte: ora por entes estatais, ora por entes não estatais. Aliás, esse seria, talvez, um dos maiores indicativos de que tal ordem é reflexiva: organizações atinentes a ela não se excluem destrutivamente - sendo que, em determinados momentos, uma afirma a competência da outra sobre determinado assunto. ${ }^{3}$

O problema que guiou a elaboração deste trabalho foi: de que modo o Tribunal Arbitral do Esporte (TAS) se insere como instância decisória de caráter jurídico? A hipótese

\footnotetext{
${ }^{2}$ DUVAL, Antoine. Lex sportiva: a playground for transnational law. European Law Journal, nov/2013, v. 19, n. 6 , p. $822-842 ;$ p. 24.

${ }^{3}$ WOLF, Klaus Dieter. Patterns of Legitimation in Hybrid Transnational Regimes: The Controversy Surrounding the Lex Sportiva. Politics and Governance, 2017, v. 5, n. 1, p. 63-74; p. 66.
} 
Revista Eletrônica de Direito Processual - REDP.

Rio de Janeiro. Ano 11. Volume 18. Número 2. Maio a Agosto de 2017

Periódico Quadrimestral da Pós-Graduação Stricto Sensu em Direito Processual da UERJ

Patrono: José Carlos Barbosa Moreira. ISSN 1982-7636. pp. 437-459

www.redp.uerj.br

apresentada para tal questionamento é a seguinte: o TAS é a instância máxima de uma ordem jurídica não estatal, porém global, cujas decisões são competentes não apenas para questões de interesse puramente esportivo, mas também, que estabelecem precedentes para si próprio (o que o torna autorreferente) e dizem respeito também a questões atinentes a direitos fundamentais dos atletas e organizações.

O objetivo geral deste texto é analisar, a partir de noções basilares da Teoria dos Sistemas Sociais Autopoiéticos (tais como complexidade, transnacionalização e autopoiese), a Lex Sportiva e o Tribunal Arbitral do Esporte. Para a consecução desse desiderato, no seu primeiro momento, estabelece uma observação da Lex Sportiva, ordem jurídica não estatal e transnacional surgida da regulação dos mais variados esportes profissionais. Já no seu segundo momento, aborda-se o Tribunal Arbitral do Esporte (TAS) como principal centro emissor de juridicidade nessa ordem multicêntrica, já que se coloca como Corte máxima nas comunicações normativas em relação a vários esportes, principalmente aqueles cujos representantes compõem o Comitê Olímpico Internacional.

Para a realização deste estudo de caso valeu-se do método sistêmico-construtivista, que parte do pressuposto de que a complexidade e a diferenciação funcional experimentadas a partir da Modernidade faz emergirem na sociedade sistemas comunicativos que têm funções, programas e códigos diversos - e isso denota a impossibilidade de normatividades e de descrições omniabarcadoras da sociedade, pois cada sistema comunicativo (sendo Direito, Política, Economia e Ciência bons exemplos seus) observa o entorno (que é constituído pelos demais sistemas), é cognitivamente aberto, mas sua organização é fechada - e, assim, cada sistema reorganiza o observado no entorno a partir da sua própria autopoiese (entendida como autorreferência, principalmente).

O Direito seria, assim, um sistema comunicativo autopoiético, sendo seu código binário descritível como "em conformidade ao direito/contrário ao direito"; já o seu programa seria o conjunto de todas as decisões ainda válidas anteriores tomadas (judiciais, doutrinárias, interpretações de leis, etc.) para cumprir a função precípua do sistema - a estabilização de expectativas normativas na sociedade.

\section{Lex Sportiva como exemplo de um Direito transnacional}


Revista Eletrônica de Direito Processual - REDP.

Rio de Janeiro. Ano 11. Volume 18. Número 2. Maio a Agosto de 2017

Periódico Quadrimestral da Pós-Graduação Stricto Sensu em Direito Processual da UERJ

Patrono: José Carlos Barbosa Moreira. ISSN 1982-7636. pp. 437-459

www.redp.uerj.br

Para melhor compreender a Lex Sportiva ${ }^{4}$ como ordem normativa de caráter jurídico, deve-se entender, preliminarmente, o sistema do Direito como constituído de comunicações (e não de indivíduos ou de instituições/organizações, de modo propriamente dito, mas sim, das comunicações estabelecidas entre tais entes), sendo multicêntrico em uma sociedade mundial complexa, observado e compreendido de forma policontextural, ${ }^{5}$ fragmentado em razão das forças centrífugas que operam em tal sociedade.

Em outras palavras, deve-se aceitar que, no atual cenário globalizado e complexo, não mais cabe falar de constitucionalização apenas naquilo que tange ao Estado: este continua a exercer um importante papel político-jurídico mundial, uma organização de ampla gama de abrangências; porém, não mais capaz de normatizar a complexidade social como um todo. Através da emersão de ordens jurídicas que se autovalidam e autorreferenciam, sem a necessidade de uma legitimação estatal que lhes outorgue força. O Direito multicêntrico é um direito que comunica, também, para além do Estado. Assim, surgem novos âmbitos de constitucionalização da sociedade mundial: ${ }^{6}$

a) Lex mercatoria, ordem jurídica atinente às contratações e decisões, em sua maioria, arbitrais, em âmbito privado de grandes empresas transnacionais, conglomerados financeiros, $\mathrm{OMC}$, etc.;

b) Lex digitalis, ordem atinente às regulações de origem privada da internet em âmbito mundial, sendo seu mais representativo órgão o ICANN - Corporation for Assigned Names and Numbers);

c) Lex technica (ordem representada pelas normas direcionadas à produção em nível mundial, tais como as da International Organization for Standardization (ISO) e da Social Accountability International;

\footnotetext{
4 "O neologismo "Lex Sportiva" é usado como direta referência à lex mercatoria, contudo, indica o conjunto de regras desportivas transnacionais" (LATTY, 2011, p. 37, tradução nossa)

${ }^{5}$ Noção desenvolvida por Gotthard Günther. Para o autor, a lógica aristotélica seria monocontextural, ou seja, algo é "conforme a norma" ou "não conforme a norma", impossibilitando uma terceira opção, racionalidade insuficiente para o atual estágio de hipercomplexidade, onde variadas lógicas são possíveis, formando várias contexturalidades ordenadas pelo binômio "conforme/não conforme", que se retro-observam em uma estrutura de extrema complexidade (GÜNTHER, 2004, s/p). De forma bastante genérica, policontexturalidade pode ser definida, seguindo a lógica de Günther, como uma pluralidade de contextos, ou seja, uma multiplicidade de autodescrições da sociedade.

${ }^{6}$ TEUBNER, Gunther. Fragmentos constitucionais: constitucionalismo social na globalização. Coord. Marcelo Neves et al. São Paulo: Saraiva, 2016.
} 
Revista Eletrônica de Direito Processual - REDP.

Rio de Janeiro. Ano 11. Volume 18. Número 2. Maio a Agosto de 2017

Periódico Quadrimestral da Pós-Graduação Stricto Sensu em Direito Processual da UERJ

Patrono: José Carlos Barbosa Moreira. ISSN 1982-7636. pp. 437-459

www.redp.uerj.br

d) Lex sportiva, atinente ao conjunto de organizações (não estatais), suas normas e decisões vinculantes de conflitos relativos ao exercício do esporte profissional.

Se na Modernidade, a centralização do Direito na figura do Estado identificava o fenômeno jurídico com os atos estatais, negando juridicidade às manifestações desligadas desse modelo, na esteira da globalização (difusão espacial das comunicações), a multiplicidade de centros de racionalização de sentido faz com que não seja possível atribuir uma existência unitária aos acontecimentos sociais. ${ }^{7}$ A forma de racionalidade monocontextural foi, e continua, importante para a história do pensamento, mas demonstra ser insuficiente para a descrição do cenário hipercomplexo atual, com variadas formas de comunicação e pluralidade de centros. "O Estado-nação soberano da modernidade entra em colapso, ou, ao menos, esse conceito é transformado". ${ }^{8}$

$\mathrm{Na}$ proliferação de ordens jurídicas transnacionais que a hipercomplexidade social evidencia, a Lex Sportiva surge da conexão entre direito e esporte, a partir das associações esportivas trasnacionais, responsáveis pela profissionalização dos mais variados esportes, a partir do progressivo aumento da prática esportiva, bem como a observação, pela economia, do esporte como mercadoria e a associação de marcas ao ganho de performance dos atletas vencedores.

Ao final do Século XIX e início do Século XX, inúmeras agremiações, estabelecidas exclusivamente para a prática esportiva profissional, foram surgindo e se estabelecendo em federações nacionais e internacionais, responsáveis por regular os diversos esportes. ${ }^{9} \mathrm{~A}$ internacionalização do esporte foi responsável pelo surgimento dos diversos códigos de regras, formulados pelas federações internacionais de cada esporte, com adaptações propostas pelas experiências das inúmeras federações nacionais. Esse processo foi o primeiro passo para o estabelecimento da Lex Sportiva, já que passaram a existir, nesse momento, regras esportivas transnacionais para as diversas modalidades esportivas.

\footnotetext{
7 FORNASIER, Mateus de Oliveira; FERREIRA, Luciano Vaz. Complexidade, globalização e regulação jurídica: a conduta das empresas transnacionais e suas possibilidades de normatização. Scientia Iuris, v. 19, Londrina, p. 73-100, 2015; p. 76.

${ }^{8}$ ROCHA, Leonel Severo; DA LUZ, Cícero Krupp. Lex mercatoria and governance: the polycontexturality between law and state. Revista da Faculdade de Direito Sul de Minas, v. 28, Pouso Alegre, p. 105-126, jan./jun. 2009; p. 117, tradução nossa.

9 A Federação Internacional de Natação foi fundada em 1908, a Federação Internacional de Halterofilismo, fundada em 1905, enquanto a Federação Internacional de Futebol foi fundada em 1904, já com uma série de federações nacionais existentes, caso da Football Association (Federação Inglesa de Futebol), responsável por estabelecer o primeiro livro de regras do esporte e mais antiga federação reguladora, fundada em 1863.
} 
Revista Eletrônica de Direito Processual - REDP.

Rio de Janeiro. Ano 11. Volume 18. Número 2. Maio a Agosto de 2017

Periódico Quadrimestral da Pós-Graduação Stricto Sensu em Direito Processual da UERJ

Patrono: José Carlos Barbosa Moreira. ISSN 1982-7636. pp. 437-459

www.redp.uerj.br

As diferentes ordenações normativas versando sobre diversas modalidades esportivas, inicialmente, não possuíam vínculos entre si, estabelecendo quais as formas permitidas de ação e reação durante os jogos. Todavia, as comunicações normativas esportivas, acompanhando a evolução da sociedade, incrementaram sua complexidade, passando a impactar em questões de direitos individuais, tais como: liberdade contratual e profissional; nacionalidade e possibilidade de competição em equipes; e, mesmo, acesso à Justiça, uma vez que as Federações Internacionais criaram sofisticados sistemas de processamento e julgamento dessas situações, absolutamente desvinculados dos Estados, versando sobre situações que, nas comunicações normativas estatais, deteriam natureza constitucional.

O estabelecimento de refinados códigos de conduta e de ética, interligados entre si; o surgimento de tribunais arbitrais internos às diversas federações, nacionais e internacionais, bem como o Tribunal Arbitral do Esporte como instância máxima esportiva; e a criação de uma Agência Mundial Antidoping (WADA), elevaram a complexidade das comunicações esportivas. A associação dos códigos e tribunais internos às federações, vinculadas pelo Comitê Olímpico Internacional (COI) e pela regulação mundial antidopagem, fez com que a Lex Sportiva afirmasse sua pretensão de autonomia como uma ordem jurídica transnacional, capaz de estabilizar expectativas em nível global, formada, exclusivamente, na seara civil privada.

Um primeiro estágio de discussão acerca da juridicidade e da autonomia de uma ordem esportiva transnacional propriamente jurídica seria atinente ao questionamento acerca da possibilidade de um direito transnacional. ${ }^{10}$ Mas este parece superado em razão do reconhecimento de ordens jurídicas não estatais, em nível transnacional, integrantes do sistema multicêntrico do Direito, como a Lex Mercatoria e a Lex Digitalis. Especificamente em relação à Lex Sportiva como ordem jurídica transnacional, alguns autores, como Edward Grayson, tentaram negar sua existência, dizendo que não haveria um "direito desportivo transnacional" (transnational sports law), somente um fenômeno. denominado de "esportes e o direito" (Sports and the Law), consistindo em uma análise de como o Direito, especificamente o estatal, se aplica ao domínio do esporte.

\footnotetext{
${ }^{10}$ Que se escolheu tratar como ordem jurídica, já que, perante a Teoria dos Sistemas Sociais Autopoiéticos, só há um sistema jurídico que, por se apresentar multicêntrico, possibilita a existência de diversas ordens jurídicas, de diferentes níveis.
} 
Revista Eletrônica de Direito Processual - REDP.

Rio de Janeiro. Ano 11. Volume 18. Número 2. Maio a Agosto de 2017

Periódico Quadrimestral da Pós-Graduação Stricto Sensu em Direito Processual da UERJ

Patrono: José Carlos Barbosa Moreira. ISSN 1982-7636. pp. 437-459

www.redp.uerj.br

Não existe, na teoria do direito, nenhum objeto de estudo que possa ser chamado de direito desportivo. Não há fundamento jurídico; tanto o common law quanto a equidade, não criaram nenhum conceito de direito exclusivamente relacionado ao esporte. Cada área do direito aplicável ao esporte não difere de como ela é aplicada para qualquer outra categoria da teoria do direito. ${ }^{11}$

Essa doutrina foi superada por se ater às comunicações estatais, desconsiderando aquilo que é observado e comunicado pelas instituições esportivas, nacionais e internacionais, de forma autônoma e com um alto grau de estruturação e validade, caso do Comitê Olímpico Internacional, do Tribunal Arbitral do Esporte e da Agência Mundial Antidoping.

Um segundo estágio dessa discussão, que reconhece haver um fenômeno jurídico surgido do encontro entre direito e esporte, que não se encerra dentro dos domínios dos Estados, se importa em compreender se Lex Sportiva pode ser enxergada como uma ordem jurídica transnacional. O ponto fulcral está no sentido que o uso do termo transnacional guarda.

Uma ordem jurídica transnacional é formada pelo vínculo estrutural entre sistemas e organizações privadas autorregulatórias; é na esfera civil privada que o conceito de ordem jurídica transnacional se desenvolve, já que se refere a atores privados não estatais que detêm capacidade de regular a si próprios. A Lex Sportiva, estabelecida como todas as comunicações desportivas globais, autoproduzida e autorregulada, com seus próprios atos jurídicos (elementos ou operações), normas jurídicas (estruturas), procedimentos jurídicos (processos) e, mesmo, uma dogmática jurídica (reflexão da identidade), pode ser considerada uma ordem jurídica transnacional autônoma. ${ }^{12}$

\footnotetext{
${ }^{11}$ GRAYSON, Edward. Sport and the law. 2. Ed. Londres: Butterworths, 1994, p. 37, tradução nossa. Ver, também, para maiores aprofundamentos: LATTY, Franck. Transnational sports law. International sports law journal. 2011-1/2; p. 37, tradução nossa.

${ }_{12}$ Adota-se, como significado da expressão "ordem jurídica" conforme o enunciado por Marcelo Neves: "[...] dentro de um mesmo sistema funcional da sociedade mundial moderna, o direito, proliferam ordens jurídicas diferenciadas, subordinadas ao mesmo código binário, isto é, 'lícito/ilícito', mas com diversos programas e critérios. Verifica-se, dessa maneira, uma pluralidade de ordens jurídicas, cada uma das quais com seus próprios elementos ou operações (atos jurídicos), estruturas (normas jurídicas), processos (procedimentos jurídicos) e reflexão da identidade (dogmática jurídica). Disso resulta uma diferenciação [entre ordens] no interior do sistema jurídico, [a qual] não se limita, porém, à diferenciação segmentária entre ordens jurídicas estatais com âmbitos territoriais de validade delimitados. Além disso, não há só uma diferenciação de 'níveis' entre ordem jurídica estatal, supranacional e internacional, mas também a diferenciação funcional de ordens jurídicas transnacionais, desvinculadas , por sua transterritorialidade, do direito estatal" (NEVES, 2009, p. 115-116).
} 
Revista Eletrônica de Direito Processual - REDP.

Rio de Janeiro. Ano 11. Volume 18. Número 2. Maio a Agosto de 2017

Periódico Quadrimestral da Pós-Graduação Stricto Sensu em Direito Processual da UERJ

Patrono: José Carlos Barbosa Moreira. ISSN 1982-7636. pp. 437-459

www.redp.uerj.br

Como uma ordem transnacional, a Lex Sportiva não é regulada pela lógica territorial, sua competência não é verificada como soberania em relação a um espaço geográfico, mas, sim, por um tema específico, como o esporte. Nesse sentido, a regulação desse tema global tem como limite o mundo, sem barreiras, se impondo de forma transversal. De forma geral, a Lex Sportiva é formada como um híbrido entre o "Direito Internacional do Esporte" - as normas relativas às regras dos esportes, inscrições em campeonatos, registro de atletas e suas transferências mundiais - e o "Direito Global do Esporte" - ordem autônoma transnacional criada pelas instituições privadas globais responsáveis pelos esportes. ${ }^{13}$

É possível aprofundar a observação sobre a formação da Lex Sportiva a partir das premissas doutrinárias de Ken Foster, ${ }^{14}$ o que permite a identificação de quatro "tipos" de regras que são aplicadas no âmbito dessa ordem jurídica transnacional. O primeiro é formado pelas "regras do jogo". Cada esporte possui suas regras e leis próprias sobre como são disputadas as partidas, estabelecidas pelas federações internacionais, como, por exemplo, quantos atletas representam cada equipe, tempo de jogo, contagem de pontos, etc. As regras do jogo, ainda que façam parte do programa da ordem jurídica desportiva, não são revisáveis pelas Cortes arbitrais do esporte, eis que sua criação e alteração somente se dá pelos órgãos legislativos das Federações Internacionais. Em outras palavras, não há um tribunal arbitral com poder judicial de revisar uma regra do jogo - exceto se tal regra for arbitrária ou ilegal em comparação com princípios gerais do Direito (Direito Desportivo Internacional), também inerentes à Lex Sportiva. ${ }^{15}$

${ }^{13}$ LUZ, Cícero Krupp da. Os entrelaçamentos entre ordens legislativas: a análise crítica da diplomacia parlamentar e do processo legislativo nos casos União Europeia/Estados-membros e FIFA/Brasil. 203f., Tese (Doutorado em Direito) - Programa de Pós-Graduação. Instituto de Relações Internacionais, Universidade de São Paulo, São Paulo, 2014, p. 119.

${ }^{14}$ FOSTER, Ken. Is there a global sports law? Entertainment Law. Vol 2, n. 1, Coventry: University of Warwick, 2003, p. 1-18; p. 5-9.

${ }^{15}$ Discussão nesse sentido foi levada a julgamento frente ao Tribunal Arbitral do Esporte quando, nos Jogos Olímpicos de Atlanta/1996, o boxeador francês Christophe Mendy foi desqualificado por um golpe contra as regras (Mendy v. AIBA; J.O. Atlanta 1996). O atleta francês propôs reclamação formal junto à Associação Internacional de Boxe Amador (AIBA), que rejeitou seu pedido, que recorreu ao TAS, objetivando que seu golpe fosse considerado legal. Na decisão final, a Câmara Arbitral ad hoc (formada para processar e julgar discussões provenientes dos Jogos Olímpicos, com máxima brevidade, pela concentração de disputas no curto prazo da competição) rejeitou a demanda de Mendy, sob alegação de que há diferença entre o que pode ser submetido à discussão judicial (regras de direito, rule of law) e o que não pode (regras do jogo), com exceção para regras do jogo que violem os valores do jogo limpo e os princípios do Direito, como permitir que os boxeadores matem um aos outros. Disponível na internet em: <http://jurisprudence.tas-cas.org/Shared\%20Documents/JO\%2096006.pdf>. Acesso em 20 out. 2016. 
Revista Eletrônica de Direito Processual - REDP.

Rio de Janeiro. Ano 11. Volume 18. Número 2. Maio a Agosto de 2017

Periódico Quadrimestral da Pós-Graduação Stricto Sensu em Direito Processual da UERJ

Patrono: José Carlos Barbosa Moreira. ISSN 1982-7636. pp. 437-459

www.redp.uerj.br

O segundo tipo de normas é formado pelos "princípios éticos do esporte". Ou seja, não são normas técnicas sobre o jogo em si, mas regramentos sobre integridade e fair-play (jogo limpo, fruto do movimento olímpico), regidos pelos códigos de ética das federações internacionais, do COI e da WADA. Essas normas são descritas como a essência do espírito esportivo, ou seja, os princípios esportivos que fundamentam, até mesmo, por trás as regras do jogo, que podem ser divididos em quatro elementos básicos do esporte: i) a incerteza do resultado; ii) honestidade e integridade do esporte, como a proibição de todas as pessoas ligadas aos esportes (atletas, treinadores, membros de federações e dos comitês olímpicos) apostarem em resultados de partidas, mesmo sendo uma conduta legal; iii) esportividade ou espírito esportivo (do inglês sportsmanship, sem tradução direta ao português), que se refere à boa-fé depositada nos atletas e treinadores, no sentido de que se obrigam a seguir as regras do jogo; iv) a própria "característica" esportiva, ou seja, o raciocínio de que mudanças nas regras do jogo podem ter consequências econômicas e esportivas capazes de alterar a característica do esporte - em outras palavras, a consciência de que as alterações nas regras do jogo devem considerar as características específicas de cada esporte e modalidade, com assessoria de especialistas no assunto, sem submissão a revisões externas.

O terceiro tipo de regras é o Direito Desportivo Internacional (ou Direito Internacional do Esporte), que são os princípios gerais do Direito que são aplicados, também, ao esporte, como o devido processo, justo e equitativo, o direito à ampla defesa, proporcionalidade, proibição do enriquecimento sem causa, pacta sunt servanda e rebus sic standibus, ou seja, o que se pode chamar de rule of law no desporto, princípios do Direito que não podem ser ignorados pela Lex Sportiva, já que atua sob o código do sistema jurídico, direito/não-direito; Por fim, o quarto tipo de regras, é o Direito Global do Esporte, mencionado supra, que descreve os princípios que emergem das regras e regulações das federações internacionais esportivas como uma ordem privada, através dos seus contratos e estatutos, ${ }^{16}$ demonstrando a capacidade da Lex Sporitva em estabelecer seus elementos ou operações, estruturas, processos e sua reflexão da identidade jurídica própria, afirmando sua autonomia.

\footnotetext{
${ }^{16}$ FOSTER, Ken. Is there a global sports law? Entertainment Law. Vol 2, n. 1, Coventry: University of Warwick, 2003, p. 1-18; p. 5-9.
} 
Revista Eletrônica de Direito Processual - REDP.

Rio de Janeiro. Ano 11. Volume 18. Número 2. Maio a Agosto de 2017

Periódico Quadrimestral da Pós-Graduação Stricto Sensu em Direito Processual da UERJ

Patrono: José Carlos Barbosa Moreira. ISSN 1982-7636. pp. 437-459

www.redp.uerj.br

Gunther Teubner ${ }^{17}$ indica que a autonomia jurídica se desenvolve em três fases lógicas. Numa fase inicial, que o autor chama de direito socialmente difuso, os elementos, estruturas, processos e limites do discurso jurídico são exatamente iguais àqueles da comunicação social geral, que seria, ainda, heteroproduzido através da referência a fatores externos, já que as expectativas são construídas com base nas normas sociais e em um contexto de coordenação de condutas; a segunda fase, um direito parcialmente autônomo emerge quando o discurso jurídico passa a definir seus próprios componentes, usando-os de forma operativa, ou seja, esses componentes se autonomizam através da autodescrição e autoconstituição; ${ }^{18}$ a última fase da autonomia jurídica emerge quando os componentes do sistema são articulados entre si num hiperciclo, tornando o direito autopoiético. Essa autopoiese jurídica somente pode aparecer caso "as relações auto-referenciais circulares componentes do sistema sejam constituídas por forma a permitirem a sua própria articulação e interligação num hiperciclo auto-reprodutivo", ${ }^{19}$ ou seja, quando os critérios usados para a identificação de normas jurídicas forem constituídos com referência em componentes internos ao próprio sistema jurídico, ou, no caso da Lex Sportiva, dentro da própria ordem jurídica.

Com o aporte à lição de Teubner, é possível uma identificação de autonomia e juridicidade como ordem transnacional da Lex Sportiva, de forma que sua validade, vigência e alcance são autoproduzidos e autorreproduzidos, através de contratos, códigos de conduta, de ética e de seus tribunais arbitrais esportivos, com inexistência de comunicações estatais. A Lex Sportiva, portanto, possui três elementos que garantem sua autonomia, como forma de complementar os tipos de regras que lhe são inerentes: a. suas normas transnacionais são geradas pelas regras e práticas das federações internacionais do esporte; b. possui uma jurisprudência única, formada a partir dos tribunais arbitrais esportivos, com princípios gerais do Direito, mas, também, com seus princípios próprios, diferentes daqueles das Cortes Estatais; c. é constituída de forma autônoma em relação às ordens estatais, ou seja, o fundamento da Lex Sportiva não deriva de qualquer tratado entre Estados, mas, sim, dos acordos e contratos firmados entre organismos reguladores dos esportes, que são

\footnotetext{
${ }^{17}$ TEUBNER, Gunther. O direito como sistema autopoiético. Lisboa: Fundação Calouste Gulbenkian, 1989, p. 80.

${ }^{18}$ TEUBNER, Gunther. O direito como sistema autopoiético. Lisboa: Fundação Calouste Gulbenkian, 1989, p. 80-81.

${ }^{19}$ TEUBNER, Gunther. O direito como sistema autopoiético. Lisboa: Fundação Calouste Gulbenkian, 1989, p. 84.
} 
Revista Eletrônica de Direito Processual - REDP.

Rio de Janeiro. Ano 11. Volume 18. Número 2. Maio a Agosto de 2017

Periódico Quadrimestral da Pós-Graduação Stricto Sensu em Direito Processual da UERJ

Patrono: José Carlos Barbosa Moreira. ISSN 1982-7636. pp. 437-459

www.redp.uerj.br

independentes dos Estados em que estão sediadas, havendo, inclusive, prevenções contra a aplicação das ordens Estatais, com sanção ao ingresso nas Justiças nacionais.

Aliás, ao menor movimento dos Estados, na tentativa de regular as federações internacionais, sua mobilidade lhes permite que se estabeleçam em outro local. Exemplo dessa mobilidade é o caso do atleta americano Harry "Butch" Reynolds contra a Associação Internacional de Federações de Atletismo (IAAF), que, em 1990, suspendeu o atleta por dois anos, após positivo para substância proibida pela IAAF, o que o impedira de participar das seletivas para as Olimpíadas de 1992. O atleta apresentou uma série defesas nas esferas administrativas e arbitrais dentro da hierarquia da IAAF, contudo, em razão da falta de êxito nessas esferas, acionou a "justiça comum”, ingressando com demanda no Distrito do Sul de Ohio, sustentando que o exame que lhe foi aplicado fora realizado de forma negligente, o que invalidaria o resultado, postulando pelo recebimento de indenização pelos danos morais sofridos, requerendo que a punição sofrida fosse considerada uma difamação. A IAAF, negando a jurisdição da corte distrital, não compareceu à audiência, o que gerou uma sentença favorável ao atleta, condenando a Federação ao pagamento de 27,4 milhões de dólares de indenização. Com isso, Reynolds iniciou processo de execução desse valor, requerendo penhora sobre valores de patrocinadores americanos da IAAF, momento em que a Federação enviou representante à Corte distrital, apenas para arguir a falta de jurisdição, o que, em sentença final, já em sede recursal, foi compreendido como argumento válido, dispensando do pagamento da indenização estipulada. ${ }^{20}$ Ademais, em função dessa intervenção estatal, a IAAF alterou sua sede para o Principado de Mônaco, ratificando sua transnacionalidade e mobilidade.

O caráter transnacional é reforçado, também, pela forma deslocalizada com que as normas esportivas são produzidas. Como a Lex Sportiva engloba todas as modalidades esportivas, suficientemente organizadas em nível mundial, as federações internacionais de cada esporte são responsáveis pela produção do Direito Global do Esporte e do Direito Desportivo Internacional, seguindo a diferenciação posta acima, visto que tais organizações possuem “órgãos legislativos" e, não raramente, “órgãos judiciários”, responsáveis por processar e julgar possíveis descumprimentos da ordem estabelecida.

\footnotetext{
${ }^{20}$ BITTING, Mellisa R. Mandatory, binding arbitration for Olympic athletes: is this process better or worse for
} job security. Florida State University Law Review, v. 25, issue 3, 1998, p. 655-678. 
Revista Eletrônica de Direito Processual - REDP.

Rio de Janeiro. Ano 11. Volume 18. Número 2. Maio a Agosto de 2017

Periódico Quadrimestral da Pós-Graduação Stricto Sensu em Direito Processual da UERJ

Patrono: José Carlos Barbosa Moreira. ISSN 1982-7636. pp. 437-459

www.redp.uerj.br

Ou seja, cada federação ou organização esportiva em nível mundial pode representar um centro emissor de juridicidade interno à Lex Sportiva, o que reforça sua transnacionalidade, multicentrismo e policontexturalidade. As federações internacionais possuem um sofisticado sistema interno, dividido em diferentes órgãos que exercem funções legislativas, executivas e de judiciário dentro da hierarquia de cada Federação, conforme disciplina do jurista belga Luc Silance, atuando com base nos textos de seus Estatutos, Códigos de Ética e Conduta, bem como nos documentos da Agência Mundial Antidoping. ${ }^{21}$

As federações esportivas de nível internacional são constituídas de sua assembleia geral, formada a partir dos representantes das federações nacionais de cada esporte, com vezes de poder legislativo, responsável por estabelecer e revisar as regras em vigor; um comitê executivo com responsabilidade de gerenciar a federação internacional; bem como comissões de resolução de litígios, com força para impor sanções, cumprindo o papel de judiciário nos sistemas jurídicos das federações, internacionais e nacionais. ${ }^{22}$

A título de exemplo, todos os esportes pertencentes ao Movimento Olímpico ${ }^{23}$ atuam com base no Código Mundial Antidoping. Entretanto, esportes que não fazem mais parte dos Jogos, e outros que jamais integraram as Olímpiadas, mantêm seus Estatutos e Códigos de Ética harmônicos com o Código Mundial Antidoping, reforçando o caráter mundial e transnacional da Lex Sportiva e sua autonomia em frente aos Estados e outros organismos internacionais, supranacionais.

Como já mencionado, um dos elementos que reforça a autonomia da Lex Sportiva e seu caráter de ordem jurídica é a existência de vasta jurisprudência, surgida a partir das comunicações dos tribunais arbitrais internos às federações nacionais e internacionais, que formam um sistema hierárquico e complexo de graus recursais. Merece destaque o Tribunal Arbitral do Esporte (TAS), que figura como centro agregador da jurisprudência da Lex Sportiva, ainda que não seja o único, porque funciona como órgão de apelação máximo

\footnotetext{
${ }^{21}$ A Agência Mundial Antidoping - WADA (World AntiDoping Agency, na sigla em inglês) foi estabelecida em 1999, fundada pelo movimento esportivo, é um órgão independente de inteligência, atuando na pesquisa e desenvolvimento de métodos antidopagem em nível esportivo, responsável pela criação e monitoramento do Código Mundial Antidoping, documento que harmoniza as políticas antidopagem em nível mundial. Disponível na internet em: 〈https://www.wada-ama.org/en/who-we-are>. Acesso em 10 maio de 2017.

${ }^{22}$ SILANCE, Luc. Lex sportiva. Le sport et le droit civil. 2001. Disponível na internet em: <laboratoire-droitsport.fr/wp.../Le-sport-et-le-droit-civil-2001.doc>. Acesso em 10 maio 2017, p. 33, tradução nossa.

${ }_{23}$ Dados retirados da página oficial do Movimento Olímpico. Disponível na internet em: <https://www.olympic.org/sports〉. Acesso em 10 de maio de 2016.
} 
Revista Eletrônica de Direito Processual - REDP.

Rio de Janeiro. Ano 11. Volume 18. Número 2. Maio a Agosto de 2017

Periódico Quadrimestral da Pós-Graduação Stricto Sensu em Direito Processual da UERJ

Patrono: José Carlos Barbosa Moreira. ISSN 1982-7636. pp. 437-459

www.redp.uerj.br

previsto nos estatutos de todos os esportes pertencentes ao Movimento Olímpico, vinculados ao Comitê Olímpico Internacional, bem como todos os demais esportes que adotam o Código Mundial Antidoping.

\section{Tribunal Arbitral do Esporte como principal centro emissor da Lex Sportiva}

A Lex Sportiva, com seu caráter descentralizado, transnacional e multicêntrico, emerge a partir de um grande número de tribunais arbitrais, atuantes em caráter interno às Federações Internacionais e, mesmo, nas Federações continentais ou nacionais, com variação conforme a competição em disputa. Assim, considerando a posição privilegiada que o TAS encontra nas comunicações desportivo-jurídicas, faz-se necessária uma melhor análise de como se dá sua atuação, na busca por demonstrar que há uma jurisprudência assentada, proveniente desse Tribunal, em demandas que versam sobre o esporte, mas que o aporte jurídico possibilita o estabelecimento de um diálogo com outras ordens jurídicas, mesmo as estatais.

O estabelecimento dos Jogos Olímpicos Contemporâneos ocasionou o paulatino aumento da prática esportiva, com o surgimento de muitas e diversas federações nacionais e internacionais. Com a extrema profissionalização esportiva, bem como a observação, pela economia, do esporte como uma mercadoria, as federações internacionais passaram a estabelecer câmaras e tribunais internos. Contudo, inexistia uma autoridade independente capaz de julgar, com força vinculante, causas desportivas entre atores de diversas nacionalidades, obrigando, com isso, a observação sobre a criação de uma instância capaz de resolver os litígios esportivos.

Essa situação perdurou até 1982, quando o COI nomeou um grupo de trabalho responsável pelo preparo do estatuto e regramento daquilo que se tornaria o atual Tribunal Arbitral do Esporte, com sede na cidade suíça de Lausanne, no sentido de criar uma autoridade especializada na área esportiva, com capacidade de resolução dos litígios internacionais através de um procedimento célere e flexível, que fosse pouco oneroso e que não se imporia aos atletas e federações, ficando livre à disposição das partes. Em 1983 o COI 
Revista Eletrônica de Direito Processual - REDP.

Rio de Janeiro. Ano 11. Volume 18. Número 2. Maio a Agosto de 2017

Periódico Quadrimestral da Pós-Graduação Stricto Sensu em Direito Processual da UERJ

Patrono: José Carlos Barbosa Moreira. ISSN 1982-7636. pp. 437-459

www.redp.uerj.br

aprovou oficialmente o estatuto do TAS, que entrou em vigor em 30 de junho de 1984, operando desde tal data. ${ }^{24}$

Antes da criação do TAS não havia uma instância máxima capaz de formular decisões vinculantes no esporte. ${ }^{25}$ A Corte tem características híbridas, pois combina a não estatalidade das cortes arbitrais com o respeito a precedentes jurisprudenciais próprios, de modo similar ao que Cortes estatais costumam fazer. ${ }^{26}$ Sendo assim, se pode visualizar, na operação de tal instância, uma característica reflexiva bastante acentuada, já que, apesar de estar desvinculado de qualquer poder estatal, vale-se do exemplo das Cortes desse tipo para melhor organizar seus procedimentos.

A atuação do TAS foi bastante restrita nos primeiros anos de funcionamento, por conta de sua "não imposição" aos atletas e federações, dependendo da convenção entre os litigantes para que a arbitragem fosse realizada pelo Tribunal, sendo que o "Requerente" interpunha seu pedido junto ao TAS, que devia ser acompanhado da convenção de arbitragem entre as partes, que, caso inexitosa uma primeira tentativa de conciliação entre os litigantes, iniciaria o procedimento arbitral.

Porém, a publicação do Guia de Arbitragem, em 1991, colocou nos estatutos das entidades esportivas cláusula excluindo a possibilidade de recurso a qualquer tribunal ordinário, criando um procedimento recursal diferenciado para os litígios provenientes de decisões tomadas pelos tribunais internos das federações internacionais. $\mathrm{O}$ estabelecimento do TAS como instância recursal às decisões das federações, foi a primeira tentativa na busca por uma coerência e congruência interpretativa na ordem jurídico-desportiva, independentemente de qual o esporte ou federação internacional estivesse sendo regulado. Pela força do COI, responsável por prover o funcionamento do TAS, as federações internacionais ligadas ao Movimento Olímpico passaram a vincular-se à cláusula de recurso, adotando o TAS como instância última.

O primeiro caso diferencial para a evolução e afirmação do TAS, após a cláusula de recurso, se deu em 1992, quando o cavaleiro alemão Elmar Gündel recorreu de decisão da

\footnotetext{
${ }^{24}$ Informações retiradas da página oficial do Tribunal Arbitral do Esporte. Disponível na internet em: <http://www.tas-cas.org/en/general-information/history-of-the-cas.html >. Acesso em 10 de maio de 2017.

${ }^{25}$ DOWNIE, Rachelle. Improving the Performance of Sport's Ultimate Umpire. Melbourne Journal of International Law, nov/2011, v. 12, n. 2, p. 315-330; p. 316.

${ }^{26}$ COCCIA, Massimo. International Sports Justice: The Court of Arbitration for Sport. European Sports Law and Policy Bulletin, 2013, v. 1, p. 23-76; p. 75.
} 
Revista Eletrônica de Direito Processual - REDP.

Rio de Janeiro. Ano 11. Volume 18. Número 2. Maio a Agosto de 2017

Periódico Quadrimestral da Pós-Graduação Stricto Sensu em Direito Processual da UERJ

Patrono: José Carlos Barbosa Moreira. ISSN 1982-7636. pp. 437-459

www.redp.uerj.br

Federação Equestre Internacional - FEI, que o havia desqualificado, suspendido por três meses e multado o atleta em CHF\$ 1.500,00 (mil e quinhentos francos suíços), após doping em seu cavalo. Em sede recursal máxima, o TAS manteve sua desqualificação, após análise da contraprova do exame antidoping. ${ }^{27}$ Irresignado, o atleta interpôs demanda junto ao Tribunal Federal Suíço, país que sedia o TAS, contestando a validade da sentença, alegando que fora prolatada por tribunal sem a condição de imparcialidade e independência, necessárias para um tribunal arbitral, baseado no fato de que a FEI é vinculada ao COI, responsável por manter o funcionamento do TAS.

O Tribunal Federal suíço, contudo, se declarou incompetente para o julgamento, reconhecendo a qualidade do TAS como tribunal arbitral autônomo e independente. Entretanto, destacou que as ligações estreitas entre o Tribunal e o COI, em que pese a autonomia do órgão judicial, poderiam ser problemáticas quando o próprio Comitê fosse parte em possível demanda (NEGÓCIO, 2011, p. 71). O caso Gündel foi paradigmático em razão do reconhecimento da autonomia do TAS, e, consequentemente, da Lex Sportiva, sendo que o Tribunal Federal Suíço se impediu de reformar a decisão arbitral, Todavia, as ressalvas quanto à dependência do TAS em relação ao COI foram compreendidas e uma série de reformas implementadas, no sentido de assentar a independência do Tribunal Arbitral do Esporte frente ao Comitê Olímpico Internacional.

O estatuto do TAS foi completamente revisado, ficando mais eficiente, tanto em sua atuação quanto na estrutura, com o objetivo de fazê-lo independente do COI, sendo aprovadas as alterações durante a "Convenção sobre a constituição do Conselho Internacional em Arbitragem sobre Esporte”, realizada em junho de 1994, conhecida como Convenção de Paris. Nesse documento, foi criado o Conselho Internacional em Arbitragem sobre Esporte, órgão responsável por cuidar do funcionamento e financiamento do TAS, retirando tal encargo do COI.

Após a Convenção de Paris, entrou em vigor, em novembro de 1994, o Código de Arbitragem em Matéria de Esporte (TAS, 2017), consolidando as reformas votadas e aprovadas na Convenção e resolvendo a independência financeira e estrutural do TAS frente ao COI. O Código aprovado criou duas turmas de arbitragem distintas dentro do TAS,

27 TAS. Gündel v. FEI, 1992. Disponível na internet em: <http://jurisprudence.tascas.org/Shared\%20Documents/63.pdf>. Acesso em 21 out. 2016. 
Revista Eletrônica de Direito Processual - REDP.

Rio de Janeiro. Ano 11. Volume 18. Número 2. Maio a Agosto de 2017

Periódico Quadrimestral da Pós-Graduação Stricto Sensu em Direito Processual da UERJ

Patrono: José Carlos Barbosa Moreira. ISSN 1982-7636. pp. 437-459

www.redp.uerj.br

separando os litígios julgados pelo Tribunal em instância única e última. Essa alteração estrutural reforçou a posição privilegiada do TAS como centro emissor de juridicidade interno à Lex Sportiva, já que na Convenção de Paris, todos as federações internacionais de esportes olímpicos e os comitês olímpicos nacionais reconheceram a jurisdição do TAS e passaram a incluir, em seus estatutos, cláusulas de arbitragem se remetendo ao Tribunal como última ou única instância Além disso, o Código Mundial Antidoping, aprovado pela Agência Mundial Antidoping em 2003, prevê, em seu artigo 13, o TAS como instância responsável pela decisão final sobre litígios envolvendo casos de doping. ${ }^{28}$

O Código de Arbitragem em Matéria de Esporte estabeleceu o número mínimo de cento e cinquenta árbitros para o exercício das funções do Tribunal, com mandato de quatro anos, renovável por mais quatro, divididos entre a Turma de arbitragem ordinária, para os litígios que têm o TAS como instância única, e a Turma arbitral de recurso, para os litígios em que o TAS atua como instância última, formadas a partir do estabelecimento do litígio. Há, ainda, uma Turma ad hoc, desde 1996, criada especialmente para julgar, em instância única, litígios provenientes dos Jogos Olímpicos, com prazo de 24 horas para exarar sua decisão, face à concentração dos Jogos, composta por dois co-presidentes e doze árbitros presentes na Vila Olímpica durante todos os Jogos.

Como parte da Lex Sportiva, o TAS é competente para aplicar a legislação esportiva porque essa legislação assim determina, sendo, ao mesmo tempo, condicionado por ela em sua atuação, em uma relação circular. São dois, principalmente, os tipos de litígios que chegam ao TAS: a) os de natureza comercial, referentes a execução dos contratos, são, majoritariamente, tratados pelo Tribunal sob instância única; e b) os de natureza disciplinar, que chegam ao Tribunal em sede recursal, oriundos de decisões anteriores.

As decisões do TAS são responsáveis pela harmonização da Lex Sportiva, em razão de sua posição destacada na ordem jurídico-desportiva, tornando as regulações eficazes, ou seja, possui a capacidade de produzir os efeitos de suas próprias decisões, haja vista que, apesar do caráter deslocalizado da Lex Sportiva, o alto número de organismos que se vinculam ao TAS possibilita uma concretização das decisões, de maneira multilocalizada, o que reforça o caráter transnacional da ordem jurídico-desportiva. Ademais, as comunicações do TAS têm

28 WADA. Código Mundial Antidoping. Disponível na internet em: <https://wada-mainprod.s3.amazonaws.com/resources/files/wada_anti-doping_code_2009_en_0.pdf>. Acesso em 10 maio 2017. 
Revista Eletrônica de Direito Processual - REDP.

Rio de Janeiro. Ano 11. Volume 18. Número 2. Maio a Agosto de 2017

Periódico Quadrimestral da Pós-Graduação Stricto Sensu em Direito Processual da UERJ

Patrono: José Carlos Barbosa Moreira. ISSN 1982-7636. pp. 437-459

www.redp.uerj.br

função importante dentro da multicêntrica ordem jurídica da Lex Sportiva, no sentido de que estabelecem padrões interpretativos próprios.

Se a categoria da complexidade pode ser resumida seletividade forçada, ${ }^{29}$ sendo que as possibilidades de escolha sempre são maiores do que é possível apreender, todo ato decisório sempre possui, no mínimo, outra alternativa, sendo o ato de decidir uma negação de todas as outras possibilidades, com as decisões em sequência guardando um grau de previsibilidade restrito. A atuação do Direito, enquanto sistema social, é no sentido de apreensão e redução da complexidade desordenada, estabelecendo uma margem de previsibilidade. No âmbito do TAS, essa margem de previsibilidade torna possível a edificação de uma jurisprudência.

A autonomia da Lex Sportiva é reforçada pela impossibilidade de reforma das sentenças arbitrais proferidas pelo TAS por tribunais estatais. A atuação do COI, um centralizador na normatização desportiva, somada à semelhança dos estatutos das Federações Internacionais, ao menos na parte estrutural, além de um Código Mundial Antidoping, sobrelevam a Lex Sportiva a uma harmonização, ou seja, uma estabilização das expectativas normativas contrafáticas, sob o código "de acordo com o Direito/em desacordo com o Direito" (direito/não-direito). Com isso, o TAS, suscitado a pronunciar-se sobre questões jurídico-desportivas, exara decisões que formam uma jurisprudência que traz a sensação de um teor global de interpretações, com a criação de padrões interpretativos (como a não intervenção em decisões meramente técnicas, tomadas dentro do jogo, exceto sejam contrárias aos princípios gerais do direito e da desportividade), uma vez que o TAS, quando do julgamento de casos que guardem similitudes com situações passadas, usa do expediente dos precedentes (auto-observação e autorreferência) para harmonização das soluções jurídicodesportivas.

Um padrão interpretativo comumente utilizado pelo TAS é o fair play, o jogo limpo ou espírito esportivo. Em 1998, durante os Jogos Olímpicos de Inverno em Nagano, no Japão, o jogador de hóquei sueco Ulf Samuelsson foi desclassificado, pois perdera a nacionalidade sueca, em 1995, por ter-se naturalizado americano, já que a legislação da Suécia, à época, não permitia dupla nacionalidade. A Federação Internacional de Hóquei sobre o Gelo - IIHF, ao ser informada da situação, promoveu a desqualificação de Samuelsson da seleção sueca, contudo, não puniu a equipe, que, naquele momento, já havia disputado três partidas, e

${ }^{29}$ LUHMANN, Niklas. Essays on self-reference. New York: Columbia University Press, 1990, p. 84. 
Revista Eletrônica de Direito Processual - REDP.

Rio de Janeiro. Ano 11. Volume 18. Número 2. Maio a Agosto de 2017

Periódico Quadrimestral da Pós-Graduação Stricto Sensu em Direito Processual da UERJ

Patrono: José Carlos Barbosa Moreira. ISSN 1982-7636. pp. 437-459

www.redp.uerj.br

vencido duas, classificada para a próxima fase do torneio. Entretanto, o Comitê Olímpico da República Tcheca, que sequer era do grupo classificatório da Suécia, tampouco a iria enfrentar no primeiro jogo da próxima fase, contestou a decisão da IIHF, recorrendo ao TAS postulando a desclassificação da seleção sueca de hóquei sobre o gelo, sob o argumento de que esperava enfrentar, nas quartas-de-final, um adversário de nível inferior, o que seria possível caso houvesse a desclassificação da Suécia, que era a atual medalhista de ouro. A decisão do TAS, através de sua Turma ad hoc formada para os Jogos Olímpicos, invocou o fair play como padrão interpretativo. ${ }^{30}$

Considerando que a equipe tcheca não fora prejudicada pela escalação de Samuelsson na Suécia e ponderando que o fair play emana da Carta Olímpica como um princípio, o TAS rejeitou a interpretação estrita do regulamento da IIHF, que previa a decretação de derrota para equipes com atletas desclassificados por questões de nacionalidade, pois a Carta Olímpica se coloca com superioridade a todos os regulamentos desportivos olímpicos, já que a aplicação restrita dessa regra acabaria por ferir o ideal olímpico do jogo limpo, falseando o resultado final dos Jogos. Com isso, ao afastar a regra, aplicando o princípio do fair play, o TAS criou um padrão interpretativo que tem se repetindo.

O Tribunal Arbitral do Esporte se coloca como principal centro emissor de juridicidade interno à Lex Sportiva, atuando como ambiente de interpretação das regras oriundas das federações nacionais, internacionais, do Comitê Olímpico Internacional e da Carta Olímpica. O TAS observa e comunica sobre questões que vão além do ambiente jurídico-desportivo, já que os casos de dopagem, nacionalidade e liberdade de exercício profissional estão imbuídos de discussões de cunho constitucional, versando sobre direitos humanos, sendo que, para decidir sobre tais situações, são considerados, além dos estatutos e códigos, princípios gerais do Direito, como presunção de inocência, proibição da punição dupla pelo mesmo fato, nulidade da pena sem norma anterior que a defina. Ou seja, um Tribunal interpretando, aplicando e garantindo direitos humanos em uma ordem jurídica não estatal, com caráter transnacional.

30 TAS. Swedish National Olýmpic Committee v. IIHF; JO Nagano, 1998, p. 6. Disponível na internet em: <http://jurisprudence.tas-cas.org/Shared\%20Documents/OG\%2098-004-005.pdf>. Acesso em: 10 maio 2017. 
Revista Eletrônica de Direito Processual - REDP.

Rio de Janeiro. Ano 11. Volume 18. Número 2. Maio a Agosto de 2017

Periódico Quadrimestral da Pós-Graduação Stricto Sensu em Direito Processual da UERJ

Patrono: José Carlos Barbosa Moreira. ISSN 1982-7636. pp. 437-459

www.redp.uerj.br

\section{CONSIDERAÇÕES FINAIS}

A observação do Direito e da constitucionalidade apenas a partir de uma perspectiva puramente estatalistas é míope: faz parte de uma ciência jurídica que não resiste às provas impostas pela complexidade atual, na qual as organizações cujas comunicações detêm juridicidade adquiriram legitimidade, em âmbitos criados a partir da ação de certa "força centrípeta" (em relação ao "Estado-centro" detentor de sentidos políticos e jurídicos) que atingiu a sociedade e criou não apenas novos atores jurídicos, mas sim, novas ordens.

Essa complexificação social vem a significar não apenas maiores possibilidades de entrelaçamentos comunicativos entre ordem estatal e assuntos sociais os mais diversos (e.g. constitucionalização/legalização da economia; da produção técnica; das liberdades de expressão, comunicação e imagem mediante altas tecnologias; do exercício do esporte; etc.), mas também a emersão de verdadeiras ordens jurídicas não estatais, justamente no espaço de reflexividade entre organizações econômicas, técnicas/tecnológicas, esportivas e o sistema comunicativo do Direito na sociedade global/transnacional. Criam-se instâncias ordinatórias e decisórias, simétricas em relação àquelas surgidas em âmbito estatal, mas de proporções e contextualizações diversas. Desta feita, o objetivo geral do trabalho que aqui se encerra - qual seja, analisar a Lex Sportiva e o Tribunal Arbitral do Esporte a partir de noções sistêmicoautopoiéticas (principalmente no que tange à complexidade e à transnacionalização) - foi alcançado.

Ao se observar a emersão da Lex Sportiva no contexto dessa sociedade hipercomplexa, policontextural e globalizada (sem temor de se cometer pleonasmos ao se atribuir esses três adjetivos a ela), vislumbra-se verdadeira ordem jurídica não estatal, cujas autonomia, legitimidade e força vinculante são reconhecida por ordens estatais. Seus processos normativos e decisórios versam acerca de matérias de alta relevância não apenas para o esporte como atividade lúdica, recreativa ou econômica: dizem respeito a liberdades fundamentais (civis, profissionais, nacional-identitárias, dentre outras), e seus procedimentos são altamente regulamentados e tidos como legítimos pelos grupos, organizações e Estados envolvidos em causas esportivas. Com isso, tem-se que o primeiro objetivo específico desta pesquisa (qual seja, estabelecer uma observação da Lex Sportiva), foi alcançado. 
Revista Eletrônica de Direito Processual - REDP.

Rio de Janeiro. Ano 11. Volume 18. Número 2. Maio a Agosto de 2017

Periódico Quadrimestral da Pós-Graduação Stricto Sensu em Direito Processual da UERJ

Patrono: José Carlos Barbosa Moreira. ISSN 1982-7636. pp. 437-459

www.redp.uerj.br

Na referida ordem, o Tribunal Arbitral Esportivo se revela como instância máxima, revisora de decisões das mais variadas instâncias decisórias das mais variadas atividades esportivas, oriundas das mais variadas localidades do mundo. Verdadeiro híbrido, que combina a não estatalidade típica da atividade decisória arbitral ao respeito aos precedentes produzidos por si próprio. Ou seja: verdadeira Corte não estatal, cujas decisões assumem relevância fundamental para vários aspectos da vida. Assim, o segundo objetivo específico deste trabalho (abordar o Tribunal Arbitral do Esporte como principal emissor de juridicidade da Lex Sportiva) também foi cumprido.

\section{REFERÊNCIAS BIBLIOGRÁFICAS:}

BITTING, Mellisa R. Mandatory, binding arbitration for Olympic athletes: is this process better or worse for job security. Florida State University Law Review, v. 25, issue 3, 1998, p. 655-678.

COCCIA, Massimo. International Sports Justice: The Court of Arbitration for Sport. European Sports Law and Policy Bulletin, 2013, v. 1, p. 23-76.

DOWNIE, Rachelle. Improving the Performance of Sport's Ultimate Umpire. Melbourne Journal of International Law, nov/2011, v. 12, n. 2, p. 315-330.

DUVAL, Antoine. Lex sportiva: a playground for transnational law. European Law Journal, nov/2013, v. 19, n. 6, p. 822-842.

FORNASIER, Mateus de Oliveira; FERREIRA, Luciano Vaz. Complexidade, globalização e regulação jurídica: a conduta das empresas transnacionais e suas possibilidades de normatização. Scientia Iuris, v. 19, Londrina, p. 73-100, 2015.

FOSTER, Ken. Is there a global sports law? Entertainment Law. Vol 2, n. 1, Coventry: University of Warwick, 2003, p. 1-18.

GRAYSON, Edward. Sport and the law. 2. Ed. Londres: Butterworths, 1994, p. 37, tradução nossa. Ver, também, para maiores aprofundamentos: LATTY, Franck. Transnational sports law. International sports law journal. 2011-1/2.

GÜNTHER, Gotthard. Life as poly-contexturality. Vorkender, [S. 1.], fev. 2004. Disponível em: 〈http://www.vordenker.de/ggphilosophy/gg_life_as_polycontexturality.pdf >

LATTY, Franck. Transnational sports law. International sports law journal. 2011-1/2. 
Revista Eletrônica de Direito Processual - REDP.

Rio de Janeiro. Ano 11. Volume 18. Número 2. Maio a Agosto de 2017

Periódico Quadrimestral da Pós-Graduação Stricto Sensu em Direito Processual da UERJ

Patrono: José Carlos Barbosa Moreira. ISSN 1982-7636. pp. 437-459 www.redp.uerj.br

LUHMANN, Niklas. Essays on self-reference. New York: Columbia University Press, 1990.

LUZ, Cícero Krupp da. Os entrelaçamentos entre ordens legislativas: a análise crítica da diplomacia parlamentar e do processo legislativo nos casos União Europeia/Estados-membros e FIFA/Brasil. 203f., Tese (Doutorado em Direito) - Programa de Pós-Graduação. Instituto de Relações Internacionais, Universidade de São Paulo, São Paulo, 2014.

NEGÓCIO, Ramon de Vasconcelos. Lex sportiva. Da autonomia jurídica ao diálogo transconstitucional. 151f., Dissertação (Mestrado em Direito) - Programa de Pós-Graduação em Direito, PUC, São Paulo, 2011.

NEVES, Marcelo. Transconstitucionalismo. São Paulo: Editora WMF Martins Fontes, 2009. ROCHA, Leonel Severo; DA LUZ, Cícero Krupp. Lex mercatoria and governance: the polycontexturality between law and state. Revista da Faculdade de Direito Sul de Minas, v. 28, Pouso Alegre, p. 105-126, jan./jun. 2009.

SILANCE, Luc. Lex sportiva. Le sport et le droit civil. 2001. Disponível na internet em: <laboratoire-droit-sport.fr/wp.../Le-sport-et-le-droit-civil-2001.doc>. Acesso em 10 maio 2017.

TAS. Código de Arbitragem em Matéria do Esporte. Disponível na internet em: $<$ http://www.tas-cas.org/fileadmin/user_upload/Code_2016_final_en_.pdf >. Acesso em 22 out. 2016.

TAS. Gündel v. FEI, 1992. Disponível na internet em: <http://jurisprudence.tascas.org/Shared\%20Documents/63.pdf> . Acesso em 10 maio 2017.

TAS. Swedish National Olýmpic Committee v. IIHF; JO Nagano, 1998, p. 6. Disponível na internet em: <http://jurisprudence.tas-cas.org/Shared\%20Documents/OG\%2098-004005.pdf>. Acesso em: 10 maio 2017.

TEUBNER, Gunther. Fragmentos constitucionais: constitucionalismo social na globalização. Coord. Marcelo Neves et al. São Paulo: Saraiva, 2016.

TEUBNER, Gunther. O direito como sistema autopoiético. Lisboa: Fundação Calouste Gulbenkian, 1989.

WADA. Código Mundial Antidoping. Disponível na internet em: <https://wada-mainprod.s3.amazonaws.com/resources/files/wada_anti-doping_code_2009_en_0.pdf>. Acesso em 10 maio 2017. 
Revista Eletrônica de Direito Processual - REDP.

Rio de Janeiro. Ano 11. Volume 18. Número 2. Maio a Agosto de 2017

Periódico Quadrimestral da Pós-Graduação Stricto Sensu em Direito Processual da UERJ

Patrono: José Carlos Barbosa Moreira. ISSN 1982-7636. pp. 437-459

www.redp.uerj.br

WOLF, Klaus Dieter. Patterns of Legitimation in Hybrid Transnational Regimes: The

Controversy Surrounding the Lex Sportiva. Politics and Governance, 2017, v. 5, n. 1, p. 6374. 